\title{
AS CARACTERÍSTICAS DA DISCIPLINA DE EMPREENDEDORISMO EM INSTITUIÇÕES DE ENSINO SUPERIOR(IES) DO ESTADO DE SANTA CATARINA
}

\author{
ADRIANA GIOVANELA \\ ANNA BEATRIZ CAUTELA TVRZSKÁ DE GOUVÊA \\ SABRINA FRÂNCIO \\ OSCAR DALFOVO
}

\section{RESUMO}

O empreendedorismo como força motriz de uma sociedade apresenta-se como um assunto importante no ambiente social e organizacional. Proporcionar formação sob o enfoque do empreendedorismo passa a configurar a realidade das IES. Esta pesquisa buscou identificar as características da disciplina de empreendedorismo nas IES de Santa Catarina por meio de pesquisa exploratória e qualitativa delineada em dois momentos: o primeiro com o levantamento de referenciais teóricos e estudo anteriormente desenvolvidos e o segundo com a coleta de dados junto a 11 IES de Santa Catarina. As cidades e IES foram escolhidas em virtude de sua representatividade em termos de tradição e qualidade, caracterizando-se como uma amostra intencional não probabilística. $\mathrm{O}$ questionário foi dividido em dois blocos: $\mathrm{o}$ primeiro intentava levantar um perfil dos docentes e o segundo a forma como a disciplina de empreendedorismo é lecionada. Os resultados apontaram que os professores da disciplina são jovens, possuem qualificação e experiência docente. As disciplinas dos diferentes cursos analisados apresentam características semelhantes quanto ao enfoque, aos autores e às técnicas de ensino. Após a análise de dados e o levantamento das características das disciplinas, apontam-se sugestões para das técnicas de ensino e a continuidade da pesquisa.

Palavras-Chave: Ensino. Empreendedorismo. IES.

\section{INTRODUÇÃO}

O papel dos empreendedores e do empreendedorismo no desenvolvimento econômico assinala-se como emergente em diversas áreas do conhecimento. Tão importante quanto a ação de empreender, o ensino do empreendedorismo é realidade nas Instituições de Ensino Superior (IES). Para um melhor entendimento sobre o assunto, cabe salientar que este é relativamente novo se comparado aos demais enfoques da área do estudo da administração. Uma breve descrição evolutiva amplia o conhecimento do tema.

Conforme Filion (2000), no início do século XVIII, a escola do pensamento econômico apresentou significativo desenvolvimento. O ideário de alguns pensadores liberais da época exigia liberdade para que cada um pudesse tirar o melhor proveito dos louros de seu trabalho. Essa corrente de pensamento que teve em Cantillon um de seus defensores, sendo que antecedeu fisiocratas como Quesnay, Turgot, Morellet, Trudaine, entre outros. Com o advento da Revolução Industrial, no Reino Unido, Cantillon voltava-se para nichos de mercado para investimentos lucrativos, onde a análise de risco era primordial na tomada de decisão. Nesta ocasião, o empreendedor era aquele que comprava matéria-prima por um preço certo para revendê-la por preço incerto. Ganhava com o lucro e na forma inovadora das transações. Empreendedorismo, risco e inovação se tornavam uma forma de negócio. Goulart, Filho e Leite (2002) apontam alguns autores que vislumbraram esta analogia. Dentre eles, destacam-se: Clark (1899), Higgins (1959), Baumol (1968), Leibenstein (1978). Filion (2000) cita ainda Schumpeter (1985) pela consolidação do conceito do empreendedorismo; 
associando-o à inovação, à criação de coisas novas e diferentes. Schumpeter (1985) utilizou o termo empreendedor e empresário para definir o indivíduo que inova não sendo, propriamente, o proprietário da empresa. Filion (2000) faz uma referência ao conceito de Schumpeter (1985) esclarecendo que tal menção tem pouco a ver com os empreendedores estudados nos dias de hoje e aponta a definição de Baumol (1993) no que tange à diferença entre empreendedor organizador de empresa e o empreendedor inovador. De fato, para os economistas, segundo apontamentos de Filion (2000), o empreendedorismo é uma função, não havendo interesse pelas características de personalidade que fazem do homem um empreendedor.

Cabe ainda destacar que entre os anos 70 e 80, os behavioristas dominaram a área do empreendedorismo. David McClelland (1976) destacou-se como estudioso na perspectiva das ciências do comportamento, sendo que impulsionou o conhecimento afirmando que as pessoas precisam de modelos comportamentais de identificação, na busca por saber quem passa a ser $\mathrm{o}$ empreendedor. Esta necessidade por modelos estaria associada ao empreendedorismo; uma vez que a necessidade de empreender vem de um desejo de realização pessoal nos negócios onde o indivíduo tem a chance de assumir riscos e ter sucesso devido à sua habilidade e não somente à sua sorte. Os estudos sobre as características empreendedoras, de forma geral, podem ser associadas à McClelland (1976). Até os anos 90 houve uma considerável ascensão das pesquisas sobre as características e traços de personalidade dos empreendedores. Muito embora os resultados tenham se mostrado surpreendentes durante cerca de 20 anos, Filion (2000) afirma que não foi possível ainda traçar um perfil psicológico do empreendedor, uma vez que as pessoas mudam conforme os contextos e circunstâncias nos quais estão inseridas e expostas e os perfis de comportamento, portanto, não são estáticos.

A partir da segunda metade dos anos 80 , vários pesquisadores recolocam a ênfase em quem é o empreendedor e o que faz um empreendedor. De qualquer sorte, o final dos anos 80 apresenta um marco onde o empreendedorismo se torna um tema de estudo em diversas esferas do conhecimento. $\mathrm{O}$ empreendedorismo tem a particularidade de reunir idéias advindas de especialistas de ciências comportamentais, econômicas, administrativas e humanas criando intercâmbios e práticas multidisciplinares.

O entendimento que permeia o assunto do empreendedorismo na economia capitalista é de que a riqueza de uma nação vai se construindo a partir da capacidade de produzir produtos e serviços necessários para seu suprimento. Neste contexto, os pequenos empreendimentos têm papel importante, visto sua relevância na capacidade de gerar emprego, renda, divisas, atuação, ocupação de nichos, flexibilidade e ativação da economia. Schumpeter (1984) definiu o empreendedor no processo de destruição criativa, o que implica na delimitação de novos produtos, métodos ou mercados, criando novas estruturas econômicas. A partir deste contexto, pode-se afirmar que ser empreendedor significa poder colocar em prática idéias próprias, inovadoras, que possam corresponder às características de personalidade e comportamento, correr riscos calculados, enfim, ter iniciativa para empreender. À luz dos conhecimentos estabelecidos até então, pode-se observar que o empreendedorismo, por tratar de comportamento, não se limita a um modelo ou definição específica, pois assim como os acontecimentos, apresenta-se como um processo de evolução contínuo. Para tanto, se fazem necessários conhecimentos mais específicos, geralmente voltados para a área de negócios.

Neste contexto, o ensino de empreendedorismo surge como uma vertente. Aprender a ser empreendedor e tornar-se um deles faz parte integrante do currículo de uma série de cursos de graduação, uma vez que o empreendedorismo e o empreendedor fazem parte dos contextos 
social, econômico, cultural e de negócios, em diversas áreas de atuação. Com este entendimento, há lugar para estudos sobre o ensino de empreendedorismo em IES que ofereçam disciplinas especificas neste tema no currículo de seus cursos. A disciplina que aborda conceitos e enfoques referentes ao empreendedorismo e ao empreendedor, desta forma, se constitui no objeto deste estudo.

O objetivo volta-se para identificar, caracterizar e analisar as características dos professores que ministram a disciplina e a própria disciplina de empreendedorismo. Os aspectos considerados se voltam para, respectivamente, idade, formação acadêmica, tempo na IES, regime de trabalho e educação continuada, e semestre em que disciplina está sendo lecionada, assuntos que integram a ementa da disciplina e são abordados em sala de aula, métodos de ensino e de avaliação da disciplina e autores considerados básicos, nos diversos cursos de graduação de onze IES catarinenses.

Este estudo pretende aumentar o foco de pesquisa para um universo maior do que o do curso de graduação e de pós-graduação em administração, entendendo que a disciplina de empreendedorismo deve estar presente nas diversas áreas de estudo. De forma geral, o entendimento é de que em todas as áreas profissionais há possibilidade de ações empreendedoras, e de que conhecimentos e habilidades neste assunto devem oportunizar um complemento aos conteúdos programáticos mais específicos de cada uma das áreas de formação.

\section{ENSINO DE EMPREENDEDORISMO: REVISÃO DE LITERATURA}

Alguns tipos de conhecimento são essenciais para se iniciar um novo negócio, sendo estes: conhecimento em administração e negócios (conhecimentos básicos em administração: recursos humanos, marketing, produção, legislação, contabilidade, finanças, entre outros); conhecimento em empreendimentos (conhecimentos específicos do negócio, produto ou serviço) e conhecimento sobre a oportunidade identificada (conhecimentos do potencial da oportunidade). Para tanto, o indivíduo poderá desenvolver e aperfeiçoar seus conhecimentos de três maneiras: trabalhar no mesmo tipo de negócio em que pretende atuar, iniciar um negócio e aprender passo a passo, ou desenvolver um plano de negócios e estudar suas etapas e minúcias. (VESPER, 1992). Dolabela (1999) afirma o que já é tácito no que diz respeito à hereditariedade do empreendedorismo: é possível ensinar e aprender a ser empreendedor.

Nos últimos vinte anos, são inúmeras as iniciativas de ensinar empreendedorismo. Os trabalhos de Menzies (1998) Dolabela (1999), Pardini e Paim (2001), Guimarães (2002), Bernardes e Martinelli (2003), Flores (2006), Souza Neto et al (2007), dentre outros, reportam esta trajetória, no mundo e no Brasil. Para Dornelas (2005) há ainda um latente esforço de organismos governamentais no que toca à disseminação da cultura empreendedora. Todavia, existe um pormenor no que tange ao ensino do empreendedorismo que deve ser considerado: ele não deve ser ministrado da maneira tradicional como são ensinadas muitas das demais matérias.

O trabalho clássico sobre o ensino do empreendedorismo apresentado por Vesper (1987) considera este enfoque, afirmando ser esta uma prática que merece atenção. $\mathrm{O}$ autor propõe novos modelos conceituais incluindo o agir como experiência didática, além do falar, ler e escrever, incentivar ainda o contato com empreendedores. Recomenda medir resultados de projetos que resultem em novos negócios. Criar uma escola empreendedora, não limitada ao calendário escolar, que contemple a produção em projetos de criação de empresas no currículo dos cursos. 
Seguindo este entendimento, é preciso agregar conhecimento teórico e prático ao mesmo tempo, no sentido de ser o professor um agente transformador que precisa incentivar em seus alunos o autoconhecimento e a obtenção de conhecimento, por meio de vivências e práticas intensas com o empreendedorismo. (MARCARINI, SILVEIRA E HOELTGEBAUM, 2003)

Pode-se apontar que o desafio torna-se instigante no que tange à construção e propagação dos conhecimentos sobre empreendedorismo nas IES, a partir do que é cerne no assunto: a inovação. Inovação não apenas como sentido de criação de novos negócios ou novas formas de capitalização de recursos financeiros, porém e, principalmente, inovação na maneira de se ministrar as aulas substituindo o foco de se formar apenas bons empregados de empresas multinacionais para indivíduos empreendedores de seus próprios negócios e das próprias carreiras.

Lowman (2004) considera que o domínio sólido da matéria, aliado às competências de comunicação, relacionamento e interação tornam-se fundamentais no ensino universitário. Desta maneira, estímulo intelectual e relacionamento interpessoal constituem o modelo bidimensional de efetividade do ensino universitário. Tais dimensões, abordadas por Lowman (2004), apontam que o estímulo intelectual está constituído por: clareza da apresentação do professor e seu impacto emocional estimulante sobre os estudantes. La Torre e Barrios (2002) afirmam que a professor passa de mero executor de projetos para um papel transformador, de agente curricular.

No ensino do empreendedorismo, sobremaneira, o professor necessita compreender as motivações dos alunos, para então adequar a metodologia de ensino, que precisa ser diferenciada e pertinente ao tema. A máxima "aprender a aprender" utilizada por Souza et al (2005, p. 204) torna-se fundamental proporcionando ao aluno proatividade com o aprendizado num sentido amplo. Neste sentido, Pardini e Paim (2001) sugerem que a abordagem do ensino do empreendedorismo seja interdisciplinar, num grande entrelaçamento entre comunidade docente e discente. Enfatizando que é papel das IES concretizar os desejos do futuro profissional do mercado por meio do conhecimento com a busca da superação e capacitação do ser social, que entende seu papel e aplica, com desenvoltura, tais conhecimentos de habilidades técnicas e científicas. O aluno, a partir desta proposta, passa a ser agente de sua própria aprendizagem e é visto como cliente e não como pessoa; intensificando sua formação técnica voltada para o mercado e sua formação de cidadão no que tange a respostas positivas à sociedade. A partir desta proposta analisada pelos autores, o professor assume papel crucial por ser ele o elemento mobilizador e motivador do grupo.

O interacionismo, que permite aos alunos a construção de seus próprios conhecimentos, é sustentado por Bizzotto e Dalfovo (2001) como abordagem de ensino do empreendedorismo nas IES. Nesta abordagem, a participação do aluno é ativa no processo de aprendizagem que passa a ser feito por meio da interação entre os outros alunos e com o professor e respectivas redes de contatos e vivências. Esta interação acaba por construir o conhecimento, evoluindo-o para um novo patamar, o que causará a descentralização do processo de aprendizagem. Os autores são categóricos ao afirmar que o ensino do empreendedorismo "não pode ser feito de forma tradicional de repasse de conteúdo". (BIZZOTTO; DALFOVO, 2001 p. 153) É preciso que o aluno construa seu conhecimento a partir de suas vivências e troca de experiências em sala de aula.

Na pesquisa descrita por Marcarini, Silveira e Hoeltgebaum (2003), onde instituições de ensino superior de Santa Catarina ligadas à ACAFE, UDESC e UFSC foram consultadas com 
o fim de apontar a relevância destas aos princípios do ensino do empreendedorismo, obteve-se como resultado que $71,43 \%$ destas têm como enfoque do curso o tema em questão nas suas grades curriculares, das quais, $70 \%$ oferecem a disciplina de empreendedorismo. Outro dado relevante é que $45 \%$ das instituições atestam a importância do ensino do empreendedorismo na formação do empreendedor. Tal relevância confirma o papel diferenciado do professor no exercício de sua profissão quando do ensino do empreendedorismo no que diz respeito à aproximação de conhecimentos teóricos com a prática diária, palestras, cursos, seminários, visitas e interfaces com empreendedores de sucesso.

Ainda complementando a idéia, Hoeltgebaum; Tomio e Dreher (2003) apontam o fenômeno do empreendedorismo como um impactante positivo sobre a economia e que necessita ser difundido. A partir daí, o ensino do empreendedorismo nas IES está sendo inserido nos currículos, com foco a formar alunos que estejam adequados às novas necessidades das organizações. Neste contexto os autores fomentam a metodologia de ensino da disciplina ideal à formação fundamenta-se por aulas dinâmicas, com exemplos práticos, numa constante atividade e interatividade - palavra-chave na moderna educação. Souza (2005) apresenta que o desenvolvimento e o aperfeiçoamento do perfil do empreendedor precisam advir da capacitação do indivíduo para criar, conduzir e desenvolver o processo criativo; assim como elaborar planejamentos, desenvolvendo suas organização e a comunidade.

É importante ressaltar que tais concepções advêm de novas percepções por parte das IES no sentido de formar o aluno capaz de gerir seu próprio negócio e não apenas ser um excelente funcionário dentro de uma corporação. Corroborando a afirmação, Dornelas (2005) afirma que já é tempo de as IES ensinarem aos jovens a essência do empreendedorismo, que se compõe de: identificação e entendimento das habilidades do empreendedor; identificação e análise de oportunidades; como ocorre o processo de inovação e o processo empreendedor; a importância do empreendedorismo no desenvolvimento econômico; como preparar e utilizar um plano de negócios; como identificar fontes e obter financiamentos para o novo negócio e como gerenciar e fazer a empresa crescer.

Ao referir-se do assunto, Dolabela (1999) afirma que o que se aprende na escola é superado pelo que se aprende fora dela. Não é preciso, portanto, acumular estoques de conhecimentos. É preciso saber aprender constantemente. Souza et al. (2005) afirma que a universidade necessita adaptar-se para enfrentar suas múltiplas tarefas de formação, pesquisa e difusão de cultura e informação estabelecendo interligações entre o mercado. Acompanhando a renovação das tarefas de formação, as IES necessitam estabelecer novas tecnologias e metodologias que proporcionem o avanço do conhecimento. Os autores acrescentam que é papel das IES "o desenvolvimento de competências empreendedoras e a disseminação da cultura do empreendedorismo". Neste âmbito, os autores afirmam que a formação precisa basear-se no desenvolvimento do autoconhecimento, por meio de ênfases em conceitos como perseverança, imaginação, criatividade e inovação. Portanto, cabe à instituição proporcionar um ambiente favorável, disponibilizando espaços de discussão e reflexão que permitam o desenvolvimento de competências empreendedoras. (SOUZA et al., 2005, p.201). Numa proposta de apresentar subsídios de apoio para o ensino do empreendedorismo, Dalfovo et al (2005) discorrem sobre um ambiente que utiliza-se da internet e que agrega o uso da tecnologia para o desenvolvimento das atividades, assim como proporciona 0 acompanhamento das atividades na disciplina e a obtenção de informações relacionadas ao conteúdo a qualquer momento, operacionalizando uma constante interação. Tal interacionismo permite exercícios básicos de elementos do empreendedorismo: construção de conhecimento, auto-aprendizado, network e abordagem vivencial. 
Tezza, Silveira e Hoeltgebaum (2006) apontam que as IES, cada vez mais, vêm aproximando o ensino à realidade do mercado, educando e formando indivíduos autônomos e criativos, ajustados às novas ordens, servindo para os que têm seu próprio negócio ou para os que trabalham em empresas. As conclusões deste trabalho mostram que há entendimento dos docentes das universidades de Santa Catarina e do Paraná "de que existe relação entre o ensino de empreendedorismo e o melhor desempenho na função de administração", sendo que as universidades deverão proporcionar conhecimentos e habilidades ao acadêmico, como administrador empreendedor. $\mathrm{O}$ ensino de empreendedorismo "é considerado relevante por estes docentes e percebido como fator de desenvolvimento e de construção de uma era de prosperidade para a sociedade.” (TEZZA, SILVEIRA E HOELTGEBAUM, 2006, p.48 e 49).

D'Alberto, Silveira e Dreher (2006), ao abordarem o ensino de empreendedorismo nos cursos de graduação em turismo, revisam os autores que se dedicam ao estudo do assunto, ao mesmo tempo em que afirmam ser este "relevante para uma formação profissional fundamentada na competência técnica e direcionada ao compromisso alicerçado na ética". Continuam afirmando que estas competências e habilidades vêm de encontro às expectativas de um mercado exigente, competitivo e receptivo "a um maior número de ações empreendedoras.” (D’ALBERTO, SILVEIRA E DREHER, 2006, p.57).

Trabalhos mais recentes apresentados nos principais eventos que incluem a temática do ensino de empreendedorismo como tema também se voltam, de forma mais especifica, para análise, discussão e reflexões sobre o assunto. Dentre outros, destacam-se: Cabral (2007); Flores, Hoeltgebaum e Silveira (2007); Campêlo e Almeida (2007); Santos, Minuzzi e Cruz (2007); Souza Neto et al. (2007a , 2007b); Dinato, Sandin e Cernach (2008); Ghobril (2008); Oliveira (2008); Paula (2008); Perera et al (2008); Peñaloza et al.(2008); Souza e CastroLucas (2008); Veloso, Ono e Silva (2008). Cabe mencionar ainda o trabalho recente de Souza, Hoeltgebaum e Silveira (2008), publicado em periódico nacional. Estes estudos, de certa forma, apresentam revisão de literatura no tema, e atestam o interesse e a preocupação permanente com a temática do ensino de empreendedorismo, no Brasil.

\section{MÉTODO DA PESQUISA}

A pesquisa foi delineada como exploratória e qualitativa. A fim de atingir o objeto de estudo da pesquisa optou-se por desenvolvê-la em duas etapas. A primeira, por meio de uma pesquisa bibliográfica, levantou-se os principais autores que têm contribuído, mais sistematicamente, com referenciais teóricos acerca do tema empreendedorismo e ensino do empreendedorismo. A partir deste referencial, que procurou revisar a literatura que mais se assemelha ao estudo aqui desenvolvido, passou-se para a segunda etapa, de coleta de dados no campo de estudo. Esta se configurou com a aplicação de um questionário com questões abertas e fechadas, sendo estruturado em duas partes. A primeira, para levantar as características dos professores respondentes quanto à idade, formação acadêmica, tempo na IES, regime de trabalho e educação continuada. A segunda, as características da disciplina de empreendedorismo quanto aos aspectos de semestre em que disciplina está sendo lecionada, assuntos que integram a ementa da disciplina e são abordados em sala de aula, métodos de ensino e de avaliação da disciplina e autores considerados básicos para o ensino da disciplina. Complementando este levantamento, os planos de ensino das disciplinas foram estudados, sob o ponto de vista de análise documental, para complementar os dados coletados.

Sendo possível identificar os respondentes, uma vez que se constituem em professores de IES que ministram a disciplina de empreendedorismo em onze IES catarinenses. A forma de escolha das IES considerou as mais representativas em termos de tradição e de qualidade 
no ensino superior catarinense, nas cidades de Balneário Camboriú, Blumenau, Brusque, Concórdia, Florianópolis, Indaial, Itajaí, Joinville, e Lages. Estas cidades também são representativas no contexto estadual, considerando ainda as diferentes regiões a que pertencem. O questionário foi enviado por correio eletrônico após contato preliminar com os professores selecionados para constituir a amostra da pesquisa. Esta foi definida de forma intencional, não probabilística, e de conveniência, buscando assegurar a adequação dos respondentes à pesquisa. O período de coleta dos dados foi transversal, em abril e maio de 2008. Os dados coletados seguiram procedimentos interpretativos, sendo as respostas consideradas por meio de análise descritiva, constituindo-se nos resultados a seguir apresentados.

\section{ANÁLISE DOS RESULTADOS}

Das onze IES pesquisadas, o curso de Administração de Empresas e suas habilitações foi o que apresentou maior representatividade quanto à disciplina de Empreendedorismo $(81,82 \%)$. Os cursos de Turismo e Hotelaria $(18,18 \%)$ e de Nutrição $(18,18 \%)$ também podem ser considerados representativos quanto a este ensino. Os demais cursos de graduação apresentaram 9,09\% de ocorrência, sendo estes: Ciências Contábeis, Gestão de Processos Industriais, Gestão Financeira, Gestão de Recursos Humanos, Técnico em Redes de Comunicação, Química, Engenharia Elétrica, Engenharia de Telecomunicações, Ciências da Computação e Sistemas de Informação. A partir destes dados infere-se que ainda é muito presente o foco do ensino do empreendedorismo apenas no curso de Administração, apesar do tema estar desabrochando em outras áreas de conhecimento.

O primeiro bloco de perguntas do questionário buscava caracterizar os professores que ministram a disciplina de empreendedorismo nos diversos cursos de graduação das IES pesquisadas. A média de idade dos docentes foi de 41,5 anos, o que demonstra professores jovens e qualificados quando apontado que $35,71 \%$ é mestre, $28,56 \%$ é doutor, e $21,43 \%$ é doutorando. A média de tempo de instituição é 7,5 anos e o regime de trabalho mais comumente apresentado foi o tempo integral (42,86\%). Isso demonstra que os professores são também pesquisadores e investem seu tempo na IES. A busca por aperfeiçoamento por parte dos docentes vem a partir de participação em cursos de outras áreas de conhecimento $(42,86 \%)$, além de cursos de especialização $(35,71 \%)$, doutorado $(28,57 \%)$, mestrado e cursos de extensão (21,43\% cada). Além disso, foram citadas participações em eventos científicos, consultorias, palestras e conversas com empreendedores como formas de aperfeiçoamento.

O segundo bloco de perguntas buscava levantar as características da disciplina de empreendedorismo nos diversos cursos de graduação, destas IES. A disciplina de empreendedorismo é lecionada, na maioria das vezes, nos últimos semestres de graduação. Indagados sobre o motivo pelo qual a disciplina é lecionada nestes semestres e não em anteriores, a unanimidade apontou que o discente está mais preparado e com mais informações para lidar com os assuntos ligados a esta disciplina, além de poder fazer ligações com o que já foi anteriormente vislumbrado em outras disciplinas.

Dentre os assuntos mais comumente abordados na ementa da disciplina, o Plano de Negócios aparece como unanimidade entre os respondentes, de acordo com a tabela 1. Os assuntos características do empreendedor (92,85\%) e etapas do plano de negócios $(92,85 \%)$ compõem as disciplinas e aparecem como mais referidos. Parecem evidenciar, segundo a maioria dos respondentes (64\%), que o empreendedorismo não se atém, apenas, aos conceitos do que seja ou compete ao empreendedor, e sim faz parte de um todo que envolve características e etapas para colocar em prática seu negócio. Os assuntos também mencionados como integrando as disciplinas de empreendedorismo foram: pequena empresa $(85,71 \%)$; implantação do plano de negócios $(85,71 \%)$ e gestão de pequenas empresas 
(71,42\%), representado, na interpretação dos respondentes, a ligação e o destaque entre os assuntos da disciplina e sua aplicação direta na vida profissional do acadêmico. Os assuntos tratados em sala de aula, dando ênfase ao empreendedorismo e ao planejamento e execução de planos de negócios, além da gestão de micro e pequenas empresas e empresas familiares são apontados pelos informantes como importantes para a formação profissional e se sustentam nos dados do Sebrae/DIEESE (2008) que apontam que no Brasil existe um total de 2.148.906 empresas formais, sendo que $97,54 \%$ destas compõem-se de micro e pequenas empresas. Dessa forma, a força de trabalho se concentra em empresas deste porte. Os demais assuntos considerados na disciplina, nas onze IES estudadas, e representando sob a designação "outros" - 50\% dos enfoques da disciplina foram: empreendedorismo corporativo, empreendedorismo social, criatividade, inovação, tomada de decisão, ética e responsabilidade social.

Tabela 1: Assuntos abordados na disciplina de Empreendedorismo nas onze IES pesquisadas, 2008

\begin{tabular}{lr}
\hline \multicolumn{1}{c}{ Principais Assuntos da Disciplina } & Incidência \\
\hline Características do Empreendedor & $92,85 \%$ \\
\hline Pequena Empresa & $85,71 \%$ \\
\hline Empresa Familiar & $71,42 \%$ \\
\hline Gestão de Micro e Pequenas Empresas & $85,71 \%$ \\
\hline Definição de Plano de Negócios & $100,00 \%$ \\
\hline Etapas do Plano de Negócios & $92,85 \%$ \\
\hline Implementação do Plano de Negócios & $85,71 \%$ \\
\hline Outros & $50,00 \%$ \\
\hline
\end{tabular}

Os autores citados por quase a totalidade de professores $(95 \%)$ e comumente adotados nas referências dos planos de ensino são dois: José Carlos Assis Dornelas e Fernando Dolabela.

Com relação às técnicas de ensino da disciplina de empreendedorismo, prevalecem as técnicas mais tradicionais, como uso da projeção em power point $(92,85 \%)$ e execução de um plano de negócios $(92,85 \%)$. A tabela 2 aponta estas características:

Tabela 2: Relação das técnicas de ensino da disciplina de empreendedorismo nas IES pesquisadas, 2008

\begin{tabular}{lr}
\hline \multicolumn{1}{c}{ Característica } & Incidência \\
\hline Projeção em Power Point de conteúdo da disciplina & $92,85 \%$ \\
\hline Debates sobre assuntos relacionados à disciplina & $85,71 \%$ \\
\hline Workshops entre turma e com demais alunos & $28,57 \%$ \\
\hline Preparação de seminários & $64,28 \%$ \\
\hline Visitas técnicas & $50,00 \%$ \\
\hline Palestras com empreendedores & $85,71 \%$ \\
\hline Execução de plano de negócios & $92,85 \%$ \\
\hline Simulação de plano de negócios com o uso de software & $50,00 \%$ \\
\hline Outros & $1,43 \%$ \\
\hline
\end{tabular}

Palestras com empreendedores e debates sobre assuntos relacionados aparecem com $85,71 \%$ nas atividades da disciplina nas IES estudadas. O contato com profissionais empreendedores atuantes torna-se importante porque o discente pode tirar dúvidas provenientes da teoria e, até mesmo, compará-las com a realidade e, assim, formar a sua opinião a respeito do tema. A preparação de seminários $(64,28 \%)$ também pode fornecer ganhos aos discentes e ao docente no que tange à troca de experiências, informações e na construção de um conhecimento em conjunto. Visitas técnicas e simulação de plano de 
negócios com o uso de software $(50,00 \%)$ aparecem logo em seguida e também podem ser consideradas como fontes de prática da teoria. Workshops entre a turma e com demais alunos $(28,57 \%)$ ainda apresenta-se como uma prática tímida nas Instituições de Ensino Superior pesquisadas. Esta interação com profissionais, alunos e professores tende a engrandecer os conhecimentos e as habilidades dos envolvidos no processo. Apenas uma pequena porcentagem de citações $(1,43 \%)$ dos docentes acrescenta outras formas de exposição da aula, como vídeo, dinâmicas de grupo, estudos de caso, eventos e feiras simulados.

Quanto aos métodos de avaliação da disciplina, como demonstra a tabela 3, também segue uma linha tradicional de execução: trabalhos em grupo e apresentação de um plano de negócios $(92,85 \%$ respectivamente) e prova $(78,57 \%)$. Apenas $14,28 \%$ dos respondentes apontam outras formas de avaliação, como: fóruns virtuais, estudos de caso e simulação de feira de negócios.

Tabela 3: Métodos de avaliação da disciplina de Empreendedorismo nas IES pesquisadas, 2008

\begin{tabular}{lr}
\hline \multicolumn{1}{c}{ Método } & Incidência \\
\hline Prova & $78,57 \%$ \\
\hline Trabalhos em grupo & $92,85 \%$ \\
\hline Apresentação do plano de negócios & $92,85 \%$ \\
\hline Outros & $14,28 \%$ \\
\hline
\end{tabular}

Estes dados devem se considerados como alerta, uma vez que a disciplina em análise tem ligação direta com a criatividade. Além disso, percebe-se que o papel do professor necessita ampliar-se para uma perspectiva mais abrangente e que estimule as diferentes inteligências (ANTUNES 1999) a fim de oportunizar estímulos para o desenvolvimento de habilidades e competências a partir de experiências inovadoras que integrem ciência e arte. Até porque, conforme Morin (2002) a reorganização do conhecimento, demandada pela realidade da sociedade, implica numa mudança de paradigma que denomina de enfoque da complexidade. Sendo assim, a docência na perspectiva da teoria da complexidade não é limitada aos aspectos disciplinares. Enfatiza-se e estimula-se o desenvolvimento do ser humano como um todo, ou seja, como aluno, profissional e indivíduo. Aspectos como a criatividade e a arte fazem sentido neste novo paradigma ao permitir uma visão mais completa Neste sentido, tornam-se imprescindíveis novos pensamentos e posturas docentes no sentido de preparar os alunos para o paradigma da complexidade da realidade.

Dessa maneira, na aplicação da arte no processo de ensino-aprendizagem apresentam-se os recursos estéticos: fotografia, pintura, leitura, vídeo, poesia e literatura. Tais recursos representam um pano de fundo para interações didáticas inovadoras que se propõem a formar um indivíduo multidimensional. $\mathrm{O}$ uso do vídeo apresenta-se como uma alternativa interessante de agregar conhecimento, por meio de experiências extras sensoriais, especialmente, na disciplina de empreendedorismo.

Após analisar as características da disciplina de empreendedorismo nestas onze IES de Santa Catarina, destacam-se algumas particularidades, conforme o quadro 1. As disciplinas de empreendedorismo da região de Blumenau, que na pesquisa compreenderam as cidades de Blumenau, Indaial e Brusque, apresentaram características mais inovadoras de ensino se comparadas com as demais regiões. 


\begin{tabular}{|l|c|l|}
\hline Região & $\begin{array}{l}N^{\text {o }} \text { créditos } \\
\text { disciplina }\end{array}$ & \multicolumn{1}{|c|}{ Características gerais da exposição da aula } \\
\hline Blumenau & 4 & $\begin{array}{l}\text { Aulas com tendência de metodologias inovadoras: uso de } \\
\text { vídeos, dinâmicas de grupo, interação com ferramentas de } \\
\text { tecnologia de informação e comunicação, simulação de feiras } \\
\text { e interações. }\end{array}$ \\
\hline Itajaí & 2 & $\begin{array}{l}\text { Aulas com tendências mais tradicionais: aula expositiva com } \\
\text { auxílio de projeção em power point e avaliação por meio de } \\
\text { provas. }\end{array}$ \\
\hline Joiville & 2 & $\begin{array}{l}\text { Aulas contendo aspectos tradicionais (aulas expositivas com o } \\
\text { auxílio de projeção em power point) e aspectos inovadores, } \\
\text { como dinâmicas e interação entre alunos. }\end{array}$ \\
\hline Lages & 4 & $\begin{array}{l}\text { Aulas com tendências mais tradicionais: aula expositiva com } \\
\text { auxílio de projeção em power point e avaliação por meio de } \\
\text { provas. Apontam-se nuances de inovações, como interações } \\
\text { com demais grupos. }\end{array}$ \\
\hline Florianópolis & $\begin{array}{l}\text { Aulas com tendências mais tradicionais: aula expositiva com } \\
\text { auxílio de projeção em power point e avaliação por meio de } \\
\text { provas. }\end{array}$ \\
\hline
\end{tabular}

Quadro 1: Levantamento das características da aula, por região

Estes dados mostram a situação em Santa Catarina. De uma maneira geral, verifica-se que a tendência pelo uso de métodos inovadores de ensino e que propiciem um aprendizado mais amplo e de uma construção de conhecimento em conjunto com o professor e com os demais colegas passa a configurar o quadro do ensino superior. Ainda que tímido, pode representar uma nova tendência no ensino superior.

Comparando com estudos anteriores neste Estado e na região sul do país, de forma geral, há compatibilidade entre os resultados. No estudo de Marcarini (2003), foram levantadas as características do ensino do empreendedorismo em IES catarinenses e pôde-se verificar que há enfoque para o empreendedorismo na estrutura curricular destas IES, seja na habilitação do curso ou como disciplina. As ementas da disciplina de empreendedorismo, as bibliografias e os semestres lecionados nas diferentes IES convergem para uma estrutura parecida. Com relação aos docentes, a pesquisa demonstrou que a grande maioria dos respondentes é graduada em administração sendo que aproximadamente $50 \%$ são formados há mais de dez anos e estão preocupados com sua atualização profissional. Há concentração de formação em mestrado e no doutorado, assim como a formação acadêmica ou educação continuada está presente, sendo que segundo os respondentes, permitiu-lhes a presença do enfoque do empreendedorismo. No que diz respeito ao ensino do empreendedorismo, os pesquisados são quase unânimes ao afirmar que o consideram importante para a formação do empreendedor e haver relação entre o ensino de empreendedorismo e o melhor desempenho da função de administrador. Com relação ao ensino de empreendedorismo nos cursos de graduação em administração catarinenses, de maneira geral, segundo os coordenadores e professores pesquisados, a disciplina deveria dar ênfase à montagem do plano de negócios, a cases de sucesso e fracasso em iniciativas empreendedoras e na auto-avaliação do espírito empreendedor. Os autores Dolabela, Filion, Degen e Tom Peters figuram entre os mais citados nesta pesquisa. Se, por um lado, os professores e coordenadores consideram o ensino de empreendedorismo nos cursos de administração extremamente importante para a formação 
do empreendedor e para o melhor desempenho da função de administrador, por outro lado também acham que o ensino deve relacionar a teoria e a prática, e que, dentro deste contexto, as propostas seriam, entre outras, a criação de incubadoras, a oferta de palestras, a disponibilização de seminários e congressos, e visitas a empresas que possam servir como exemplo de iniciativa empreendedora de sucesso ou de fracasso.

O estudo de Tezza (2004) revela que o empreendedorismo é tido como assunto importante nas estruturas curriculares das IES do Estado do Paraná e este enfoque pôde ser verificado na estrutura curricular destas IES, seja como habilitação do curso ou como disciplina. A partir da análise das ementas da disciplina de empreendedorismo pôde-se concluir que existe concordância entre os itens gestão de novos negócios, plano de negócios e empreendedorismo. Quando realizada comparação com o estado de Santa Catarina, assinalase concordância nos itens perfil do empreendedor, qualidades do empreendedor e o plano de negócios. Quanto à bibliografia das disciplinas estudadas observa-se concordância entre as IES paranaenses e catarinenses em relação aos autores Degen, Dolabela, Chiavenato e Filion. Para as fases em que são oferecidas estas disciplinas, as instituições optam por ministrá-las nos últimos períodos, quando as disciplinas básicas já foram estudadas. Isto ocorre tanto nas universidades paranaenses como nas IES catarinenses. Um comparativo entre os docentes pesquisados no estado de Santa Catarina pôde apresentar concordância em relação à ligação do empreendedorismo com a criação de novos negócios, inovação e criatividade. Pelo exposto, concluí-se, finalmente, que o ensino de empreendedorismo nos cursos de graduação em administração das universidades paranaenses vem acontecendo, porém não de forma consolidada. Dessa forma, a pesquisadora analisada propôs algumas mudanças no sentido de preparar o acadêmico para ser bem visto em relação às novas expectativas do mercado de trabalho; como um administrador empreendedor. As mudanças discorreram sobre as possíveis práticas docentes, como a ligação forte entre a teoria e a prática, a interação com ambiente, seminários e debates com empreendedores, a fim de proporcionar ao aluno experiências vivenciais de empreendedorismo.

O estudo de D'Alberto verificou o ensino do empreendedorismo nos cursos de turismo do Estado de Santa Catarina. As pesquisas demonstraram que ainda não há um enfoque para o objeto de estudo de maneira consolidada, o que assinala a necessidade de uma revisão nas grades curriculares. Às IES que oferecem a disciplina de empreendedorismo em suas grades, verificou-se que não há uma convergência de itens estudados, assim como há uma diversidade de bibliografias recomendadas. A visão de coordenadores e professores sobre as características necessárias ao empreendedor ainda está fortemente ligada à iniciativa e criatividade. A pesquisa ainda aponta que os entrevistados foram unânimes em afirmar que consideram importante o ensino do empreendedorismo para a formação do turismólogo e haver relação entre o ensino do empreendedorismo e o melhor desempenho das atividades do mesmo. Com relação ao foco da disciplina empreendedorismo os itens, plano de negócios, empreendedorismo: exemplos de sucesso e características/perfil do empreendedor apresentaram-se como assuntos mais importantes. Com relação às ferramentas didáticopedagógicas utilizadas, apresentaram-se: o estudo de caso e as visitas técnicas. A partir destas constatações, a pesquisadora afirma que torna-se necessário um empenho maior para que a disciplina seja amplamente discutida e ampliada no curso de turismo.

Com relação aos dados obtidos nesta pesquisa e os de outras pesquisas analisadas, verifica-se que o panorama do ensino de empreendedorismo, nos cursos de graduação se assemelham pela abrangência do tema, pelas características de bibliografia, semestres oferecidos e técnicas de ensino que prezem por um aprendizado vivencial, de experimentos e que ofereçam ao aluno o conhecimento e o desenvolvimento das características empreendedoras. 


\section{CONSIDERAÇÕES FINAIS}

Os professores se caracterizam, na maioria, jovens, com faixa etária média de 41,5 anos, especializados, pois a maioria $(35,71 \%)$ é mestre, com 7,5 anos, em média, de Instituição e apresenta preocupação por constante busca por aperfeiçoamento profissional (em cursos, congressos, pesquisas) e pessoal (participação em eventos e leituras em diversas áreas do conhecimento).

A disciplina de empreendedorismo se faz presente nos mais variados cursos de graduação do Estado de Santa Catarina: Administração, Turismo e Hotelaria, Nutrição, Ciências Contábeis, Gestão de Processos Industriais, Gestão Financeira, Gestão RH, Técnico em Redes de Comunicação, Química, Engenharia Elétrica, Engenharia de Telecomunicações, Ciências da Computação e Sistemas de Informação. Dessa forma, pode-se verificar que a temática é abrangente, ampla e importante para as diversas linhas de conhecimento.

O Plano de Negócios e suas etapas aparecem como unanimidade entre os respondentes como o assunto mais abordado (92,85\% dos respondentes). Parecem evidenciar, segundo a maioria dos respondentes (64\%), que o empreendedorismo não se atém, apenas, aos conceitos do que seja ou compete ao empreendedor, e sim faz parte de um todo que envolve características e etapas para colocar em prática seu negócio. Os assuntos também mencionados como integrando as disciplinas de empreendedorismo foram: pequena empresa (85,71\%); implantação do plano de negócios $(85,71 \%)$ e gestão de pequenas empresas $(71,42 \%)$, representado, na interpretação dos respondentes, a ligação e o destaque entre os assuntos da disciplina e sua aplicação direta na vida profissional do acadêmico

Os enfoques das disciplinas que tratam do empreendedorismo se assemelham, pois evidenciam a importância da ação empreendedora como propulsora da economia. Neste sentido, os autores mais citados (95\%) permanecem sendo Dolabela e Dornelas. Esta abordagem pode demonstrar a importância da disciplina frente à montagem de novos negócios e também o cunho prático ao qual ela se propõe, como afirmado pelos coordenadores de curso.

A forma de ministrar a disciplina quanto às técnicas de ensino, podem ser repensadas pelos docentes no sentido de ampliar ainda mais as experiências vivenciais dos alunos. Vale ressaltar que a visão das IES, assim como da própria evolução do mercado, está se voltando para o empreendedor como um agente transformador da sociedade e da ação empreendedora; aquele indivíduo inquieto com a inércia e a acomodação dos acontecimentos; um indivíduo constantemente em busca de aperfeiçoamento no sentido de fazer constantes ligações entre teoria e prática - o que é aprendido e o que é vivenciado. A partir desta concepção, torna-se fundamental o papel das IES no sentido de dar respaldos teóricos e vivenciais para que se oportunize ao indivíduo vivência do empreendedorismo. $\mathrm{O}$ ensino de empreendedorismo não é um tema que possa ser direcionado de forma convencional. Ele precisa, necessariamente, ser vivenciado pelos alunos num processo de autoconhecimento e auto-aprendizagem, ou seja, por meio de experiências em sala de aula; simulações e pré-testes da vida real, onde o aluno possa aumentar seu patamar de conhecimentos e aplicar diretamente na sua vida pessoal e/ou profissional.

Nesta visão, o papel do professor torna-se importantíssimo, como facilitador e incentivador para que as potencialidades dos alunos se sobressaiam e que, por meio de prática o aluno consiga adaptar os conceitos vistos com as realidades de mercado. Vesper (1973) aponta como alternativa para os professores que aprofundem ainda mais as vivências dos alunos com o gerenciamento do risco. A afirmativa torna-se pertinente, pois é preciso que o aluno saiba lidar com o risco na visão empresarial e na pessoal. 
É necessário, portanto, uma mudança de atitude por parte do professor de empreendedorismo. Cada vez mais este deve utilizar-se de recursos como criatividade e inovação, tão peculiares ao empreendedor, para que crie marcas profundas e que transforme, de certa maneira, as vivências e a maneira de pensar e agir de sua equipe. É necessário, portanto, que professores e IES trabalhem conjuntamente a fim de saírem de suas zonas de conforto e empreenderem, de fato por meio de atividades interdisciplinares, vivenciais e específicas no que diz respeito à construção e reconstrução do saber, fazendo a completa ligação entre universidade - empresas - sociedade.

A pesquisa não intenta finalizar o assunto. Configura-se como o início de uma discussão do tema. Portanto, prevê-se estudos com outras metodologias e abordagens mais específicas, percebendo ligações e interdisciplinaridade entre disciplinas de empreendedorismo e as demais disciplinas dos cursos de graduação, em cada área do conhecimento.

\section{REFERÊNCIAS}

ANTUNES, Celso. Jogos para a estimulação das múltiplas inteligências. 4. ed. Petrópolis: Vozes, 1999.

BIZZOTTO, Carlos Eduardo Negrão; DALFOVO, Oscar. Ensino de Empreendedorismo: Uma Aborgadem Vivencial. In: ENCONTRO DE ESTUDOS SOBRE EMPREENDEDORISMO E GESTÃO DE PEQUENAS EMPRESAS - EGEPE, 2, 2001, Londrina. Anais... Londrina: UEL/UEM, 2001. p. 142-153.

CABRAL, Romilson Marques. Estratégias didáticas para o ensino do empreendedorismo em cursos de Pós-Graduação Lato Sensu. In: ENCONTRO DE ENSINO E PESQUISA EM ADMINISTRAÇÃO E CONTABILIDADE - EnEPQ, 1, 2007, Recife, PE. Anais... Rio de Janeiro: ANPAD, 2007. 1 CD-ROM.

CAMPÊLO, Amanda Farias; ALMEIDA, Ana Márcia Batista. É possível desenvolver habilidades de intra-empreendedorismo em estágios supervisionados? analisando uma proposta de aproximação teórica -empírica. In: ENCONTRO DE ENSINO E PESQUISA EM ADMINISTRAÇÃO E CONTABILIDADE - EnEPQ, 1, 2007, Recife, PE. Anais... Rio de Janeiro: ANPAD, 2007. 1 CD-ROM.

D’ALBERTO, Ana Maria Ferreira, SILVEIRA, Amélia; DREHER, Marialva Tomio. O ensino de empreendedorismo nos cursos de graduação em turismo em Santa Catarina. In: In: SILVEIRA, Amélia; DOMINGUES, Maria José Carvalho de Souza. Ensino na área de administração e avaliação de instituições de ensino superior. Blumenau: Edifurb, 2006. p. 5580 .

DINATO, Maria Rosilene Sabino; SANDIN, Ângela Slagdo de Andrade; CERNACH, Ana Cláudia. Educação empreendedora: o processo de aprendizagem como fator de mudança social e tecnológica. In: ENCONTRO DE ESTUDOS SOBRE EMPREENDEDORISMO E GESTÃO DE PEQUENAS EMPRESAS - EGEPE, 5, 2008, São Paulo, SP. Anais... São Paulo: UPM/UEM/UEL, 2008. 1 CD-ROM.

DOLABELA, Fernando. Oficina do Empreendedor. São Paulo: Cultura, 1999. 
. O segredo de Luísa. São Paulo: Cultura, 1999.

DORNELAS, José Carlos Assis. Empreendedorismo: transformando idéias em negócios. 2 ed. Rio de Janeiro: Elsevier, 2005.

FILION, Jean Jacques. 2000. O Empreendedorismo como tema de estudos superiores: palestra proferida no Seminário: "A universidade formando empreendedores". Disponível em: $<$ http://www.iel.org.br/programa/empreend/discur4html >. Acesso em 06 abr. 2007.

FLORES, Danusa Cunha; HOELTGEBAUM, Marianne; SILVEIRA, Amélia. O ensino do empreendedorismo nos cursos de pós-graduação em administração no Brasil. In: ENCONTRO DE ENSINO E PESQUISA EM ADMINISTRAÇÃO E CONTABILIDADE EnEPQ, 1, 2007, Recife, PE. Anais... Rio de Janeiro: ANPAD, 2007. 1 CD-ROM.

GOULART, Íris B.; PAPA FILHO, Sudário; LEITE, Walter Lana. Empreendedorismo: uma palavra nova, uma ação urgente. Educação e Tecnologia, Belo Horizonte, v.7, n. 1, p. 42-50, jan./jun. 2002.

GHOBRIL, Alexandre Nabil et al. Mudando paradigmas para a formação de empreendedores em cursos universitários: a experiência da pré-incubadora de empresas na Universidade Presbiteriana Mackenzie. In: ENCONTRO DE ESTUDOS SOBRE EMPREENDEDORISMO E GESTÃO DE PEQUENAS EMPRESAS - EGEPE, 5, 2008, São Paulo, SP. Anais... São Paulo: UPM/UEM/UEL, 2008. 1 CD-ROM.

HOELTGEBAUM, Marianne; TOMIO, Dílson; DREHER, Marialva Tomio. Uma nova concepção do ensino do empreendedorismo: uma visão além do business plan. In: ENCONTRO DE ESTUDOS SOBRE EMPREENDEDORISMO E GESTÃO DE PEQUENAS EMPRESAS - EGEPE, 3, 2003, Brasilia. Anais... Londrina: UEL/UEM/ UnB, 2003. p. 161-170.

LA TORRE, Saturnino de; BARRIOS, Oscar (coords.). Estratégias didácticas innovadoras. Barcelona: Ediciones Octaedro, 2000.

LOWMAN, Joseph. Dominando as técnicas de ensino. São Paulo: Atlas, 2004.

MARCARINI, Adenir. O Empreendedorismo nos Cursos de Administração de Santa Catarina, Brasil. Dissertação de Mestrado. Programa de Pós-Graduação em Administração. FURB. 2003.

MARCARINI, Adenir; SILVEIRA, Amélia; HOELTGEBAUM, Marianne. O desenvolvimento do empreendedor nas universidades como instrumento de geração de novos empreendimentos. Disponível em: $<$ http://www.fgvsp.br/iberoamerican/papers/0207artigoensempfinal.pdf $>$. Acesso em 06 abr. 2008. 
MORIN, Edgar. A cabeça bem feita. 7. ed. Rio de Janeiro: Bertrand Brasil, 2002.

OLIVEIRA, Marcos André Farias de. O saber a partir de quem sabe: elementos para (re) pensar a formação em empreendedorismo. In: ENCONTRO DE ESTUDOS SOBRE EMPREENDEDORISMO E GESTÃO DE PEQUENAS EMPRESAS - EGEPE, 5, 2008, São Paulo, SP. Anais... São Paulo: UPM/UEM/UEL, 2008. 1 CD-ROM.

PARDINI; Daniel Jardim; PAIM, Lúcia Regina Corrêa. Empreendedorismo e interdisciplinaridade: uma proposta metodológica no ensino de graduação. In: ENCONTRO DE ESTUDOS SOBRE EMPREENDEDORISMO E GESTÃO DE PEQUENAS EMPRESAS - EGEPE, 2, 2001, Londrina. Anais... Londrin: UEL/UEM, 2001. p. 227-240.

PAULA, Cláudio Paixão Anastácio de. Using brasilian folk tales as an alternative approach to 'entreperneurship' in university education. In: ENCONTRO DE ESTUDOS SOBRE EMPREENDEDORISMO E GESTÃO DE PEQUENAS EMPRESAS - EGEPE, 5, 2008, São Paulo, SP. Anais...São Paulo: UPM/UEM/UEL, 2008. 1 CD-ROM.

PERERA, Luiz Carlos Jacob et al. Pode-se formar empreendedores na universidade? In: ENCONTRO DE ESTUDOS SOBRE EMPREENDEDORISMO E GESTÃO DE PEQUENAS EMPRESAS - EGEPE, 5, 2008, São Paulo, SP. Anais...São Paulo: UPM/UEM/UEL, 2008. 1 CD-ROM.

PEÑALOZA, Veronica et al. Ensino de empreendedorismo e expectativas profissionais. In: ENCONTRO DE ESTUDOS SOBRE EMPREENDEDORISMO E GESTÃO DE PEQUENAS EMPRESAS - EGEPE, 5, 2008, São Paulo, SP. Anais...São Paulo: UPM/UEM/UEL, 2008. 1 CD-ROM.

SANTOS, Paulo da Cruz Freire dos; MINUZZI, Josiane; CRUZ, Nicholas Joseph Tavares da. $\mathrm{O}$ ensino de empreendedorismo nos cursos de administração: sugestões a partir do perfil empreendedor de estudantes alagoanos e catarinenses. In: ENCONTRO DE ENSINO E PESQUISA EM ADMINISTRAÇÃO E CONTABILIDADE - EnEPQ, 1, 2007, Recife, PE. Anais... Rio de Janeiro: ANPAD, 2007. 1 CD-ROM.

SOUZA; Eda Castro Lucas de; GUIMARÃES, Tomás de Aquino. Empreendedorismo além do plano de negócio. São Paulo: Atlas, 2005.

SOUZA, Eda Castro Lucas de; CASTRO-LUCAS, Cristina. Empreendedorismo, inovação e cultura: uma experiência de ensino-aprendizagem. In: ENCONTRO DE ESTUDOS SOBRE EMPREENDEDORISMO E GESTÃO DE PEQUENAS EMPRESAS - EGEPE, 5, 2008, São Paulo, SP. Anais... São Paulo: UPM/UEM/UEL, 2008. 1 CD-ROM.

SOUZA, Sheila de; HOELTGEBAUM, Marianne; SILVEIRA, Amélia. O ensino do empreendedorismo nos cursos de graduação em administração do Paraná e do Rio Grande do Sul. Dynamis Revista Tecno-científica, Blumenau, v.1, n.14, p.12-22, jan./mar. 2008.

SOUZA NETO, Silvestre Prado de et al. A influência do ensino de empreendedorismo no potencial empreendedor do aluno. In: ENCONTRO DE ENSINO E PESQUISA EM ADMINISTRAÇÃO E CONTABILIDADE - EnEPQ, 1, 2007, Recife, PE. Anais... Rio de Janeiro: ANPAD, 2007. 1 CD-ROM. 
SOUZA NETO, Silvestre Prado de et al. O empreendedorismo e o ensino universitário. In: ENCONTRO DA ANPAD, 31, 2007, Rio de Janeiro, RJ. Anais...Rio de Janeiro: ANPAD, 2007. 1 CD-ROM.

TEZZA, Gisele Orli Adam. O Ensino do Empreendedorismo nos Cursos de Administração das Universidades do estado do Paraná, Brasil. Dissertação de Mestrado. Programa de PósGraduação em Administração. FURB. 2004.

TEZZA, Gisele Orli Adam; SIVEIRA, Amélia; HOELTGEBAUM, Marianne. A educação empreendedora nos cursos de graduação em administração de Santa Catarina e do Paraná, Brasil. In: SILVEIRA, Amélia; DOMINGUES, Maria José Carvalho de Souza. Ensino na área de administração e avaliação de instituições de ensino superior. Blumenau: Edifurb, 2006. p. $35-54$.

VELOSO, Andrés Rodriguez; ONO, Arnaldo Turuo; SILVA, Natacha Bertoia da. O impacto do perfil familiar e da universidade no desenvolvimento do potencial empreendedor. In: ENCONTRO DE ESTUDOS SOBRE EMPREENDEDORISMO E GESTÃO DE PEQUENAS EMPRESAS - EGEPE, 5, 2008, São Paulo, SP. Anais...São Paulo: UPM/UEM/UEL, 2008. 1 CD-ROM.

VESPER, Karl H. Views on college courses in venture initiation. Academy of Management Journal, 1973, v, 16 n. 3, p. 519-522, set. 1973.

. New venture experience. Seatle: Vector Books, 736 p.

VESPER, Karl H; GARTNER, W.B. Measuring progress in entrepreneurship education. Journal of Business Venturing, v. 12 n. 5, p. 403-21,1997. 